Cite as: Abdishakur W. Diriye, Osman M. Jama, Ren Chong \& Abdulhakim M. Abdi (2021) Value of cultural worldviews and message framing for the acceptability of sustainable land use zoning policies in post-conflict Somalia, Journal of Environmental Planning and Management, DOI: 10.1080/09640568.2021.1974360

\title{
Value of cultural worldviews and message framing for the acceptability of sustainable land use zoning policies in post-conflict Somalia
}

\author{
Abdishakur W. Diriye ${ }^{\mathrm{a}, \mathrm{b} *}$, Osman M. Jama ${ }^{\mathrm{a}, \mathrm{b}}$, Ren Chong ${ }^{\mathrm{a}}$ and \\ Abdulhakim M. Abdic \\ ${ }^{a}$ Research Center of Environmental Policy and Management, School of Public Affairs, \\ University of Science and Technology of China, Hefei, People's Republic of China; ${ }^{b}$ Department \\ of Public Administration, Faculty of Economics and Management Science, Mogadishu \\ University, Mogadishu, Somalia; ${ }^{c}$ Centre for Environmental and Climate Science, Lund \\ University, Lund, Sweden
}

\begin{abstract}
Public acceptability is important for sustainable land use zoning policy to be successfully implemented. This study examined the effectiveness of tailoring messages with cultural worldviews to induce positive attitudes and improve public acceptability of sustainable land use zoning policy in a post-conflict setting. A total of 538 participants were randomly divided into three groups. Two were treatment groups and received promotional information about a hypothetical land use zoning policy, and one group was the control group and received no promotional information. The results indicate that information provision results in positive attitudes and higher public acceptability of land use zoning policy. Arguments that correspond to participants' cultural worldviews generated more positive attitudes and higher acceptability than arguments that conflict with their cultural worldviews. This study recommends targeting messages with peoples' cultural worldviews as an effective strategy in inducing positive attitudes and higher acceptability for sustainable land use zoning policy in Somalia.
\end{abstract}

Keywords: cultural worldviews; message framing; sustainability; land use; deforestation

\section{Introduction}

Sustainable land use is crucial to maintaining the capacity of ecosystems to deliver essential environmental services that meet growing global demand (Lambin et al. 2014). Land use determines livelihoods, and various detrimental effects of unsustainable land uses are evident in countries recovering from conflict (Kiage 2013; Omuto, Balint, and Alim 2014; Suarez, Árias-Arévalo, and Martínez-Mera 2018), such as Somalia where land use seems to be in a somewhat chaotic state after three decades of conflict (Omuto, Balint, and Alim 2014). One particular unsustainable land use that can be observed in Somalia is deforestation, which triggers land degradation (Omuto, Balint, and Alim 2014). And a key land use policy that has the potential to reduce deforestation is land use zoning (Nolte et al. 2017; Bruggeman, Meyfroidt, and Lambin 2015). The term "land use zoning" signifies regulations on permission, prohibition, or land use preference. It aims to support lawful land use by spatially delimiting

*Corresponding author. Email: geesood08@mail.ustc.edu.cn 
land into areas of specific use practices (Bruggeman, Meyfroidt, and Lambin 2015; Lambin et al. 2014). Land use zoning policy alters livelihood goals to achieve intended outcomes. Thus, it requires public acceptance to be effective.

Public acceptance is increasingly recognized as vital for successful land use policies (Pleger, Lutz, and Sager 2018; Pleger 2017; Williams 2014) and is a growing field of research (Busse and Siebert 2018). Land use zoning has commonly been implemented through regulatory measures such as penalties and restrictions (Lambin et al. 2014; Nolte et al. 2013). However, acceptance of such land use policy measures is low compared to other policy measures such as incentives (Pleger 2017) that call for more deliberate attempts to improve public perceptions and ensure the intended policy outcome.

Leading, and influencing, public opinion in a favorable direction is considered a viable strategy for improving public acceptability of land use policies (Williams 2011). One way to shape public opinion is by providing information (Teel et al. 2006). Much attention has been paid to examining the effectiveness of information provision, but information alone hardly triggers behavioral change (McKenzie-Mohr and Schultz 2014). One reason why information seems to fail in changing behaviors is that it often overlooks individual characteristics that engage the recommended behavior (Barr and Gilg 2007).

Previous studies indicate that environmental problems involve conflicting cultural worldviews (Markle 2019; Price, Walker, and Boschetti 2014), which influence people's thought process in response to divisive public discourses (Douglas and Wildavsky 1983; Thompson, Ellis, and Wildavsky 1990). Such cultural worldviews can lead different groups of people to choose, disregard, and or interpret information about policy measures differently (Kahan and Braman 2006; Leiserowitz 2006). Cultural worldviews may thus constrain the effect of information campaigns in triggering behavioral changes. Thus, the effectiveness, or lack thereof, of information campaigns in triggering behavioral changes is a growing concern among researchers and policy practitioners (Steg and Vlek 2009; McKenzie-Mohr and Schultz 2014). Considering this, Jang (2013) pointed out the need to examine the interaction between information attributes and individual predispositions. In this context, a growing body of literature has examined how individual predispositions, such as values and political ideologies, influence the effectiveness of information campaigns (Arpan et al. 2018; Graham and Abrahamse 2017). However, knowledge on ways in which information on government policies can be tailored to cultural worldviews and the effectiveness of such information in changing public perception is limited (West, Bailey, and Winter 2010). Here, we draw from the cultural theory of risk and message framing to explore whether messages that are tailored to cultural worldviews can effectively influence attitudes and acceptability of land use zoning policy in Somalia.

The remainder of this paper begins with the theoretical perspective followed by hypotheses formulation. In the next step, the paper lays down the materials and methods employed, including the study region, experimental survey design, participants, procedure, key measures, and statistical analysis. Subsequently, the paper presents the results followed by relevant interpretations and discussion with implications and limitations. The final section concludes the paper.

\section{Theoretical perspective}

This section presents the foundations of the cultural theory of risk, conceptualizes the acceptability phenomenon, and then links it with information and message framing theories. 


\subsection{The cultural theory of risk}

The cultural theory of risk (thereafter Cultural Theory) posits a prototype in serving as a theoretical basis to understand conflicting societal and environmental issues. The Cultural Theory was first developed by Douglas (1970) to predict and explain the societal patterns of values and beliefs through which people understand and relate to their world (Verweij et al. 2006). Various scholars then revised and further expanded the theory (Thompson, Ellis, and Wildavsky 1990; Schwarz and Thompson 1990).

The Cultural Theory distinguishes four lifestyles, often called worldviews; egalitarianism, hierarchism, individualism, and fatalism (Douglas and Wildavsky 1983), and postulates that these worldviews determine how people handle almost everything (Verweij et al. 2006). Each worldview has a unique perception of nature and a shared understanding of the resources and needs by which its members justify their activities (Thompson, Ellis, and Wildavsky 1990). Egalitarians view nature as vulnerable to human activities and thus requiring careful management. The ideals of egalitarianism also emphasize social equality. Individualists view nature as resilient such that it cannot be harmed by human activities. Individual interests are emphasized, and nature conservation is not prioritized. Hierarchists view the nature as resilient only within the limits where human activities can cause collapse resulting in irreversible damage. Hierarchists attribute the responsibility of regulating human-environment relationships to experts and governments. Fatalists view nature as unpredictable and unmanageable, and hence they enjoy the benefits of the natural resources available to them (Schwarz and Thompson 1990).

Although not without criticism, the Cultural Theory is useful in comprehending conflicting interests, and these cultural worldviews are associated with the acceptance of different policy prescriptions (Rissman, Kohl, and Wardropper 2017, Cherry, Kallbekken, and Kroll 2017). For example, egalitarians are found to be environmentally friendly, while individualists are less environmentally friendly (Markle 2019). Further, egalitarians are found to favor environmental policies that limit vehicle usage, and individualists are found to see the same policies as unimportant (Steg and Sievers 2000). Mixed results have been documented for hierarchy and fatalists (Steg and Sievers 2000; Markle 2019; Price, Walker, and Boschetti 2014). Besides this, the four cultural worldviews are not mutually exclusive, but an individual can have inconsistent worldviews (Hoogstra-Klein, Permadi, and Yasmi 2012; Price, Walker, and Boschetti 2014). In particular, individualism and fatalism are correlated (Halik and Verweij 2018; Price, Walker, and Boschetti 2014; Lima and Castro 2005) and are aggregated as one dimension "individualized cultural worldview" (Price, Walker, and Boschetti 2014). Similarly, egalitarianism and hierarchism are correlated (Lima and Castro 2005, Price, Walker, and Boschetti 2014, Halik and Verweij 2018) and are aggregated as one dimension "collectivized cultural worldview" (Price, Walker, and Boschetti 2014). In summary, the individualized cultural worldview is found to frame the environment as 'elastic' to justify environmentally harmful practices and resist conservation efforts, whereas the collectivized cultural worldview is found to frame the environment as 'ductile' to recognize the vulnerability of the environment to destructive human activities and to support conservation efforts (Price, Walker, and Boschetti 2014).

The present study considers cultural worldviews as individualized and collectivized for their suitability to tailor the message and contributes to the role that these worldviews can play in messages that are aimed to enhance policy acceptability. 


\subsection{Acceptability conceptualization}

Acceptability is one among various factors affecting policy goals (Sabatier and Weible 2014) and is considered as a prerequisite condition for the effectiveness of policy designing and implementation (Ingold 2011; Kriesi and Jegen 2001). Acceptability is a broad term with different meanings concerning contexts such as public, social, and political, but overall, the term "acceptability" lacks a consistent definition especially in the area of land use (Busse and Siebert 2018). As a result, various definitions of acceptability that often overlap and contradict each other are available, and even the terms "acceptance" and "support" have been used as synonymous with acceptability (Busse and Siebert 2018). Since the concept is studied from various backgrounds, the inconsistency of its meanings may be due to the differences in these backgrounds. However, it is within this complexity, acceptability affects the success of land use policy, and therefore, the clarification of the concept is required.

The three-dimensional conceptualization proposed by the German sociologist Lucke (1995) can be a viable orientation guide to the understandings of the construct. The three dimensions are (1) the object to be accepted (the thematic reference), (2) the subject or the actor who can be an individual or a group of people, and (3) the context in which the object is accepted which can be legal, institutional, or political. Accordingly, some other scholars suggest that the definition of the concept should answer (1) what should be accepted, (2) through whom, and (3) under which circumstances or conditions (Schade and Schlag 2003). This study examines the public acceptability of hypothetical land use zoning policy aimed to reduce deforestation as unsustainable land use and asks the participants to decide either in favor of or against the proposed policy. We, therefore, describe "public acceptability" as a positive judgment by Somali citizens (the subject) toward a land use zoning policy (the object) in response to their cultural worldviews and information provided (the context/conditions).

Policy judgments such as acceptance of land use policies are determined not only by the object of research but also by the actors' values, beliefs, and cultural worldviews (Pleger 2017; Williams 2014; Cherry, Kallbekken, and Kroll 2017). Furthermore, people need to believe that the policy is an effective way of addressing the focal issue and achieving the recommended outcome (Schade and Schlag 2003), thus, communicating policy to the public may be viable to increase public acceptability. However, research indicates that people with different cultural worldviews have different attitudes toward policies aimed to improve environmental conditions (Price, Walker, and Boschetti 2014) and interpret information differently (West, Bailey, and Winter 2010). Such differences may thus result in an increased polarization and influence the effect of information on policy acceptability. Taken together, information that simply highlights the pro-environmental aspects of land use zoning policy may not be successful in inducing positive attitudes and higher acceptability, especially when the recommended behavior is associated with higher salience of a decision problem. For instance, if land use zoning restricts land use practices and imposes tax penalties, policy addressees may dismiss the information campaigns that highlight only the environmental benefits of the policy because they make judgments about what the policy means to them. As an alternative, message framing may have the potentials to overcome the pitfalls of conventional information campaigns. 


\subsection{Message framing}

Message framing is disseminating information in different ways to make it more convincing (Chong and Druckman 2007). Framing theory proposes that emphasizing particular aspects of the information can affect how the audience receives and interprets it (Chong and Druckman 2007). In terms of effectiveness, framing is found to induce changes in pro-environmental attitudes and behavioral intentions (Bolderdijk et al. 2013). It is particularly found to improve public acceptance of spatial planning policies (Pleger, Lutz, and Sager 2018). Small differences in wording in scenarios with the same monetary incentives, such as presenting a Pigovian tax as an "offset" instead of a "tax," can increase support for a measure (Hardisty, Johnson, and Weber 2010).

Framing effects are not consistent but are found to depend on various factors. Spence and Pidgeon (2010) indicate that gain framing is more effective than loss framing in inducing positive attitudes toward climate change mitigation efforts. Others suggest that highlighting local aspects or personally relevant climate change issues is more effective than emphasizing global dimensions of climate change problems (Scannell and Gifford 2013). Additionally, attribute framing was less effective than goal framing in improving public acceptance of land use policy (Pleger, Lutz, and Sager 2018). Moreover, the target group reacts unequally to different policy frames, indicating that a single framing strategy appeals to a specific segment of the population and neglects others.

On the other hand, it has been suggested that individual predispositions of issues such as values and beliefs determine the strong effect of message framing (Chong and Druckman 2007). Tailoring frames to peoples' needs and pre-existing orientations such as values are believed to be effective, as shown in previous studies (Graham and Abrahamse 2017, Abrahamse et al. 2007). However, earlier studies have an insufficient emphasis on tailoring persuasive messages with peoples' orientations to appeal to the general public. Persuasive messages are commonly framed as a collective issue that necessitates everybody to address by modifying their behaviors. This way of communication may only appeal to those with socially conscious orientations, and so, the problem lies in how to persuade those who are disinterested in the issue (von Borgstede, Andersson, and Hansla 2014).

Considering that cultural worldviews predict public acceptance of environmental policies (Cherry, Kallbekken, and Kroll 2017; Steg and Sievers 2000), we propose that it may be pertinent to frame messages in line with cultural worldviews. Here cultural worldviews can be pooled as two dimensions, i.e. individualized and collectivized (Price, Walker, and Boschetti 2014); therefore, we present two different types of arguments (message frames) to appeal to both cultural worldviews. Arguments highlighting personal benefits to be obtained from the policy (individualized arguments hereafter) and arguments highlighting collective environmental and social benefits (collectivized arguments hereafter). The underlying assumption is that individualized arguments will appeal to the people who have individualized cultural worldviews (individualists hereafter), whereas collectivized arguments will appeal to the people who have collectivized worldviews (collectivists hereafter) more effectively.

\subsection{Aims and hypothesis}

This study aims to examine whether: (1) cultural worldviews predict attitudes and acceptability of sustainable land use zoning policy; (2) communicating policy benefits 
to the general public leads to a positive attitude and improved acceptability of land use zoning policy, and (3) framing messages in line with different underlying cultural worldviews is a more effective means to eliciting positive attitude and higher acceptability. This is done using a hypothetical policy that was not previously communicated by the government. We, therefore, assume that there are no already established judgments about it.

Hypotheses 1a and 1b: As per the literature reviewed above, individualists are expected to be negatively associated $\left(\mathbf{H}_{\mathbf{1}}\right)$, and collectivists are expected to be positively associated $\left(\mathbf{H}_{\mathbf{1 b}}\right)$ with attitudes and acceptability of land use zoning policy.

Hypothesis 2: In line with the bulk of research suggesting that information provision is an integral part of shaping attitudes and behaviors about natural resource management, information provision is expected to induce a positive attitude and improved acceptability of land use zoning policy.

Hypotheses 3a and 3b: Based on the research suggesting that messages framed in line with peoples' values are more persuasive, individualists are expected to evaluate individualized arguments more positively than collectivized arguments $\left(\mathbf{H}_{\mathbf{3 a}}\right)$, and collectivists are expected to evaluate collectivized arguments more positively than individualized arguments $\left(\mathbf{H}_{\mathbf{3 b}}\right)$.

\section{Materials and methods}

\subsection{Description of the study context}

This study is conducted in Somalia, a country in the Horn of Africa that has an arid and semi-arid type of climate with a low annual average rainfall $(282 \mathrm{~mm})$ dominated by agro-pastoral communities (Omuto, Balint, and Alim 2014; Omuto et al. 2009). The country is undergoing severe land degradation with deforestation as the main source (Oduori et al. 2011; Omuto, Balint, and Alim 2014). One-third of Somalia is degraded (Omuto, Balint, and Alim 2014) and large parts of the country are at risk of transforming into a desert in 20 years if immediate action is not taken (Rembold et al. 2013). Loss of vegetation cover, soil erosion, and other degradation trends are evident across the country (Omuto, Balint, and Alim 2014, Oduori et al. 2011).

Earlier studies in the country found an estimated annual average tree loss of $2.7 \%$ between 2011 and 2013 in southern regions (Bolognesi et al. 2015), and 2.8\% between 2001 and 2006 in northeastern regions (Oduori et al. 2011). Also, another study found an estimated tree loss rate above 7\% over 5 years between 2006 and 2012 in the Lower Juba region of Southern Somalia (Rembold et al. 2013). On the other hand, vegetation loss triggers other degradation trends (Omuto et al. 2009) and involves loss of livelihood opportunities such as reduced livestock numbers, which increases poverty (Waaben Thulstrup et al. 2020).

Deforestation in Somalia is contributed to by both local charcoal demand for cooking (Omuto et al. 2009) and foreign export, which accounts for $80 \%$ of the charcoal production in Somalia (UNEP 2005). Charcoal production and export became the key source of income for militia groups such as Al-Shabaab, thus making it a security threat (Bolognesi et al. 2015, Rembold et al. 2013). This has led the United Nations Security Council to issue a ban on charcoal exports from Somalia (UNDP 2012). 
Similarly, Somalia's federal and regional governments have issued a series of prohibitions on deforestation and charcoal exportation. Despite these interventions, the effect has been little so far (Rembold et al. 2013), and recent studies have shown concern about the issue and recommended urgent policy implementation (Waaben Thulstrup et al. 2020).

Considering the challenges faced by previous interventions, Oduori et al. (2011) suggested that deforestation in the region can be mitigated through strengthening policy implementation and monitoring capabilities, coupled with cooperation between the communities and local administration. Since land use zoning has the success story of reducing deforestation in many areas, including Sub-Sahara African contexts such as Cameroon (Bruggeman, Meyfroidt, and Lambin 2015), it may also be viable in Somalia.

\subsection{Experimental survey design}

The application of experimental research design using an online survey questionnaire is justified for the present study because of its advantages. The experimental research design compares groups or conditions with different individuals and measures the treatment effect (Hamenstädt 2011). Therefore, the experiment provides a controlled condition that increases transparency and thus allows conclusions on the causal inference (Druckman et al. 2011, Iyengar 2011). Experimental research design is particularly appropriate for the assessment of policy proposals (Smith 1994), which applies to the present study. Furthermore, participants are not restricted by geographical boundaries in online experiments (Iyengar 2011) which is particularly important for studies focusing on an entire population rather than a particular segment, which is also relevant for this study. In addition, an online survey is also justified for the study because of its pluses in saving time, fewer errors in data entry, and accessibility for the target population as $68 \%$ of Somalis have access to the internet with cheap data packages (USAGM 2013).

\subsection{Participants}

565 adult participants completed the survey. After a crosscheck, problematic responses $(n=27)$ were discarded, leaving 538 valid questionnaires for further analysis. Demographic characteristics of the participants were (53.4\%) male and (46.6\%) female with an educational level of high school (19.4\%), bachelor degree (47.9\%), masters' degree (28.3\%), and Ph.D. (4.4\%), living around urban (47.5\%), sub-urban $(38.4 \%)$ and rural villages $(14.1 \%)$, see Table 1 .

\subsection{Procedure}

A pilot test $(n=30)$ was carried out to assess the clarity of the message content and enhance the validity and reliability of the survey. Following suggestions from the experts, minor modifications were performed. The actual survey was then carried out as follows: First, the survey started with a brief introduction that the government intends to implement a land use policy-actions that are intended to reduce deforestation and land degradation and the participants were informed of the survey participation rights, such as voluntary participation, confidentiality, and voluntary 
Table 1. Descriptive demographic statistics of the participants $(n=538)$.

\begin{tabular}{llr}
\hline Variable & Category & Percentage \% \\
\hline Gender & Male & $53.4 \%$ \\
Age group & Female & $46.6 \%$ \\
& Below 20 & $13.7 \%$ \\
& $20-30$ & $52.8 \%$ \\
Educational level & $31-40$ & $26.7 \%$ \\
& Above 40 & $6.8 \%$ \\
& High school & $19.4 \%$ \\
Residential area & Bachelor & $47.9 \%$ \\
& Masters & $28.3 \%$ \\
Personal income & Ph.D. & $4.4 \%$ \\
& Urban & $47.5 \%$ \\
& Town & $38.4 \%$ \\
& Village & $14.1 \%$ \\
& Less than $\$ 200$ & $42.6 \%$ \\
& \$200-\$400 & $42.2 \%$ \\
& \$400-\$600 & $10.2 \%$ \\
& Above $\$ 600$ & $5.1 \%$ \\
\hline
\end{tabular}

withdrawal following the universal ethics of the behavioral studies. Then, the participants answered questions that included their age, gender, educational attainment, personal income, residential areas, and cultural worldviews in December 2019. Secondly, the participants were randomly divided into three groups in February 2020. Two groups were designated as treatment and were presented with information promoting the potential benefits of land use zoning policy, which is intended to induce a more positive attitude and improve public acceptability. One of these two groups $(n=179)$ received individualized arguments, and the other group $(n=179)$ received collectivized arguments. The third group $(n=180)$ was assigned to be a control group and received no information. There are no significant differences in these three groups with respect to gender $(\mathrm{f}(2,538)=1.91, p>0.38)$, age $(\mathrm{f}(6,538)$ $=1.65, p>0.94)$, education $(\mathrm{f}(6,538)=5.41, p>0.49)$, residential area $(\mathrm{f}(4,538)=$ $2.30, p>0.68)$, personal income $(\mathrm{f}(6,538)=9.91, p>0.13)$ and cultural worldview $(\mathrm{f}(2,538)=1.31, p>0.52)$ (see supplementary appendix). This suggests that the random allocation was effective.

The base of the message was the same but framed in different ways to align with cultural worldviews. For instance, the individualized arguments were framed as follows: if you, as an individual, adhere to land use policies, you will get cheap meat and milk due to enough pasture for livestock, improved health due to enough herbs for traditional medicine, safety from high temperatures and flooding, and beautiful scenery for tourism. Your behavior can make a difference. In contrast, collectivized arguments were framed as follows: if as a society, we adhere to land use policies, it will reduce forest degradation in our country, protect soil erosion, and reduce droughts. Our collective behavior can make a difference and improve our environmental conditions. The credibility of the information was assessed by asking the respondents whether they thought the information was meaningful, understandable, and trustworthy. The participants answered these questions on a Likert scale of seven points ranging from not at all (1) to extremely (7). The measurements were recoded with the aim of echoing higher scores for higher credibility (individualized arguments Cronbach's $\alpha=0.838$ 
and collectivized arguments $\alpha=0.844$ ). There was no significant difference among the credibility scores of the two arguments (individualized argument: $M=5.80, \mathrm{SD}=$ $1.20, U=30054, \mathrm{Z}=-1.29, p=0.19$; collectivized argument: $M=5.84, \mathrm{SD}=1.177$, $U=30434, \mathrm{Z}=-1.06, p=0.28)$.

\subsection{Key measures}

\subsubsection{Cultural worldviews}

Cultural worldviews were assessed using eight items of cultural group membership adopted from Price, Walker, and Boschetti (2014) These measurements are short statements that indicate how people view environmental issues and their potential policy responses. The measurements were tested in previous studies and considered robust (Price, Walker, and Boschetti 2014; Halik and Verweij 2018). The individualized cultural worldview items were as follows: the natural environment is full of resources and can recover from any destructive practice by humans; the natural environment functions in a strange way and cannot be managed; people should have the freedom to use the environment irrespective of their impacts and environmental policies are just means of restricting people and generally fail. The collectivized cultural worldview items were as follows: the natural environment is delicate, and it can easily be destroyed; people have a social duty to protect the environment; people should obey the environmental policies, and the natural environment will be safe if the environmental laws are obeyed. The participants expressed their agreement on these statements by rating on a Likert scale of five points ranging from 1 (strongly disagree) to 5 (strongly agree). The mean, standard deviation and reliability averaged: $(M=3.49, \mathrm{SD}=0.86, \alpha=$ $0.73)$ for individualized cultural worldview and $(M=4.24, \mathrm{SD}=0.57, \alpha=0.81)$ for collectivized cultural worldview. The two cultural worldviews correlated with each other significantly $(r=-0.17, p=0.001)$. The collectivized cultural worldviews significantly correlated with both collectivized $(r=-0.20, p=0.001)$ and individualized arguments $(r=0.10, p=0.011)$, but individualized cultural worldview showed moderately significant correlation with collectivized $(r=-0.07, p=0.05)$ and individualized arguments $(r=0.03, p=0.05)$ (see Table 2$)$.

\subsubsection{Outcome measures}

Attitude toward the proposed land use zoning policy was assessed using three statements adopted from Vaske and Donnelly (1999) with slight changes to suit the study context. The participants were asked to express how they feel about reducing deforestation and land degradation with these strategies: (1) prohibit tree cutting and penalize anyone who does not obey, (2) prohibit and control charcoal business and export, and (3) government should decide the specific land uses of the country. The participants indicated their attitude on a Likert scale of seven points ranging from 1 (extremely negative) to 7 (extremely positive). The analysis showed a high correlation and internal consistency for these three attitude measures. The reliability, mean and the standard deviation for the attitude averaged: $(M=4.19, \mathrm{SD}=0.77, \alpha=0.90)$.

Also, the participants were asked to rate how much they would accept or reject short statements that are aimed to reduce inefficient land uses such as deforestation on a Likert scale of five points ranging from 1 (strongly reject) to 5 (strongly accept). The three statements were taken on from earlier studies on land use zoning policy 
Table 2. Means, standard deviations (SD) and Pearson correlations (r).

\begin{tabular}{lcccccccr}
\hline Variable & Mean & SD & 1 & 2 & 3 & 4 & 5 & 6 \\
\hline ICW & 3.4916 & 0.85774 & 1 & & & & & \\
CCW & 4.2435 & 0.57371 & $-0.172^{* *}$ & 1 & & & & \\
IA & 4.1912 & 0.68073 & $-0.070^{\dagger}$ & 0.032 & 1 & & & \\
C A & 3.9535 & 0.83697 & $-0.202^{* * *}$ & $0.101^{*}$ & $0.100^{*}$ & 1 & & \\
ATP & 4.1889 & 0.77172 & $-0.186^{* *}$ & $0.275^{* * *}$ & $0.401^{* *}$ & $0.397^{* * *}$ & 1 & \\
PA & 4.2212 & 0.67352 & $-0.844^{*}$ & $0.248^{* *}$ & $0.153^{* *}$ & $0.331^{* * *}$ & $0.523^{* * *}$ & 1 \\
\hline
\end{tabular}

Significance Level:

$*=p \leq 0.05$.

$* *=p \leq 0.01$.

$* * *=p \leq 0.001$.

Note: Numbers that appear in the top row correspond to the numbers that appear in the first column. $\mathrm{ICW}=$ individualized cultural worldview, $\mathrm{CCW}=$ collectivized cultural worldview, IA $=$ individualized arguments, $\mathrm{CA}=$ collectivized arguments, $\mathrm{ATP}=$ attitude toward policy, $\mathrm{PA}=$ policy acceptability.

(Lambin et al. 2014, Geneletti 2013), and were framed as follows: (1) the government should decide the specific land uses of the country such as the sites of new villages, roads, and farms, and penalize anyone who does not obey, (2) the government should control the development of land into the prime grazing and farmlands, and (3) the government should impose regulations concerning land conversion and protection of trees. The mean, the standard deviation and the reliability averaged $(M=4.22, \mathrm{SD}=0.67, \alpha$ $=0.89)$. The highest correlation $(r=0.52, p=0.001)$ in the study was observed between attitude and public acceptability (see Table 2).

\subsection{Statistical analysis}

The hypothesized relationships between the variables were examined using three-step hierarchical regression analysis in the SPSS software program. First, the two cultural worldviews were entered in the regression analysis as covariates. Secondly, the information was entered as a variable to examine how it affects the participants' attitudes and acceptability. Thirdly, message framing was entered as a moderator to examine whether the effect of information provided was moderated by the cultural worldviews. Moderation arises if the effect of a predictor variable on the outcome is dependent on another variable that significantly influences the initial pathway of interaction (Hayes 2013). The moderation analysis was displayed in a graphical format using a Microsoft Excel-based program called Modgraph-1 version 3.0 (Jose 2013).

\section{Empirical results}

\subsection{Cultural worldviews and their effect on attitudes and acceptability}

The hierarchical regression model showed that cultural worldviews are significantly associated with attitudes and of acceptability of land use policy. People with individualized cultural worldview expressed significant negative attitude toward land use policy, thus supporting part of hypothesis $\mathrm{H}_{1 \mathrm{a}}(\beta=-0.14, p \leq 0.001, \mathrm{t}=-3.02)$ whereas people with collectivized cultural worldview expressed significant positive attitude $(\beta=0.32, p \leq 0.001, t=6.61)$ and significant acceptability $(\beta=0.17$, $p \leq 0.001, t=3.42$ ) of land use zoning policy. Although we found a negative 
relationship between individualized cultural worldviews and land use zoning policy acceptability, this association lacked statistical significance. (See Table 3).

\subsection{Information provision and its effect on attitudes and acceptability}

The hierarchical regression analysis showed that information provision significantly affected public attitudes and acceptability of land use zoning policy $(\mathrm{F} \quad(3,394)=$ 54.17, $\left.p \leq 001, \mathrm{R}^{2}=0.18\right)$. Participants who received the promotional information showed more positive attitudes $(\beta=0.44, p \leq 0.001, t=10.21)$ and higher acceptability of land use zoning policy $(\beta=0.28, p \leq 0.001, t=5.97)$ compared to participants who did not receive information. The effect of information on attitudes and acceptability was compared in the two cultural worldviews. In the analysis of attitude, a significant effect of information was found only in collectivists $(\beta=0.12, p \leq 0.01$, $t=2.82$ ). In contrast, in policy acceptability analysis, a significant effect of information was found only in individualists $(\beta=0.10, p \leq 0.01, t=2.01)$. (See Table 3 and Figures $1-3)$.

\subsection{Message framing and moderation effect}

Overall, the hierarchical regression model showed an interaction between argument types and cultural worldviews, partially supporting our third hypothesis (Table 4). Although the interaction is not significant, individualists who received individualized arguments expressed a more positive attitude and significantly higher acceptability ( $\beta=0.17, p \leq 0.001, t=3.24)$ than the individualists who received collectivized arguments. On the other hand, collectivists who received collectivized arguments reported a significantly more positive attitude $(\beta=0.14, p \leq 0.001, t=3.21)$ and significant higher acceptability $(\beta=0.13, p \leq 0.001, t=2.63)$ than the collectivists who received individualized arguments. When compared, the effect of the two arguments, collectivized arguments were stronger in predicting positive attitudes, and individualized arguments were stronger in predicting higher policy acceptability (See Table 4 and Figures $4-6)$.

\section{Discussion}

This study offers evidence that cultural worldviews predict attitudes and acceptability of sustainable land use zoning policy in post-conflict Somalia, which confirms the earlier studies showing an association between cultural worldviews and environmental policy acceptance and support (Cherry, Kallbekken, and Kroll 2017, Rissman, Kohl, and Wardropper 2017). Individualized cultural worldviews were associated with a negative attitude and lower acceptability of sustainable land use zoning policy. In contrast, collectivized cultural worldviews were associated with a positive attitude and higher acceptability of sustainable land use zoning policy. More specifically, this finding corroborates previous research demonstrating that collectivized cultural worldview justifies environmental conservation practices, and the individualized cultural worldview resists the same practices (Price, Walker, and Boschetti 2014). This finding means that land use policymakers need to consider how the policy contributes and reflects these conflicting cultural worldviews to avoid unnecessary policy setbacks. In support of our second hypothesis, information provision was associated with more 


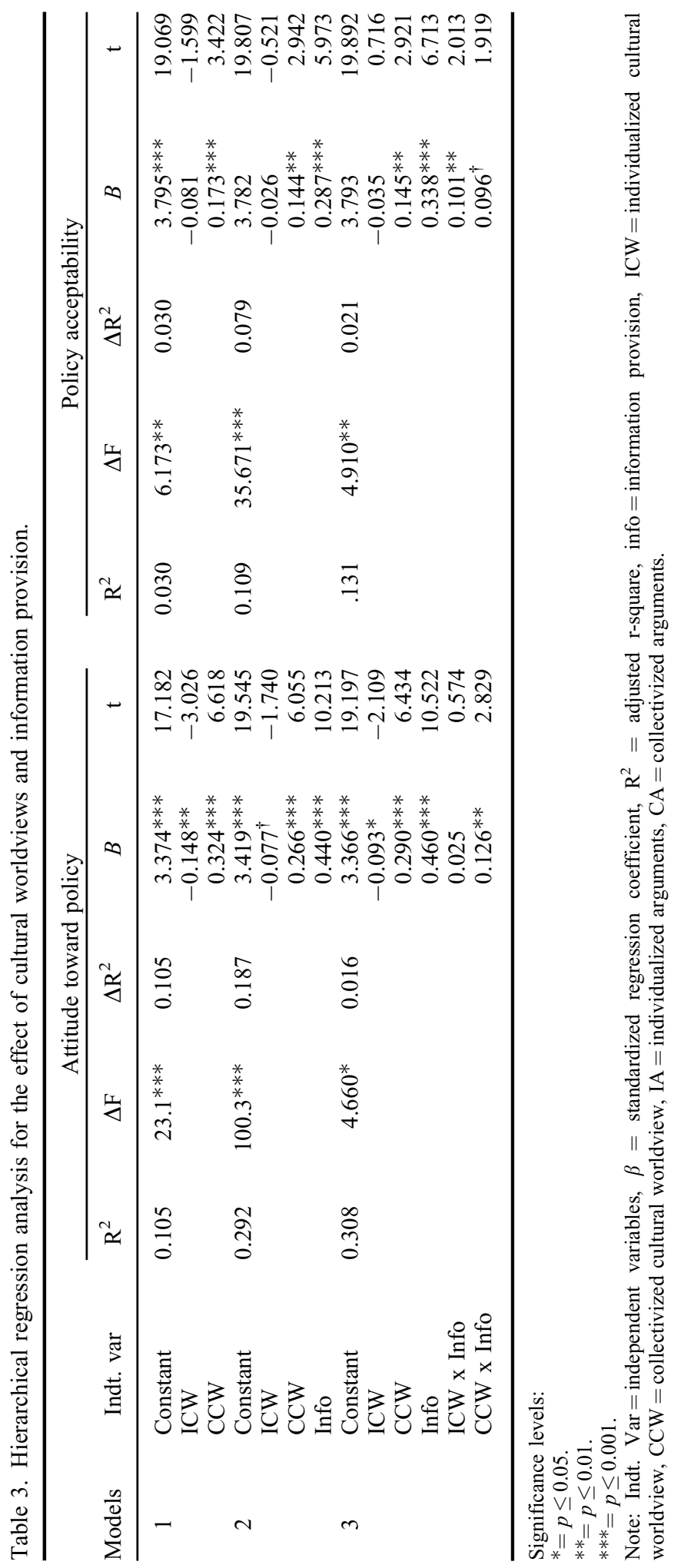




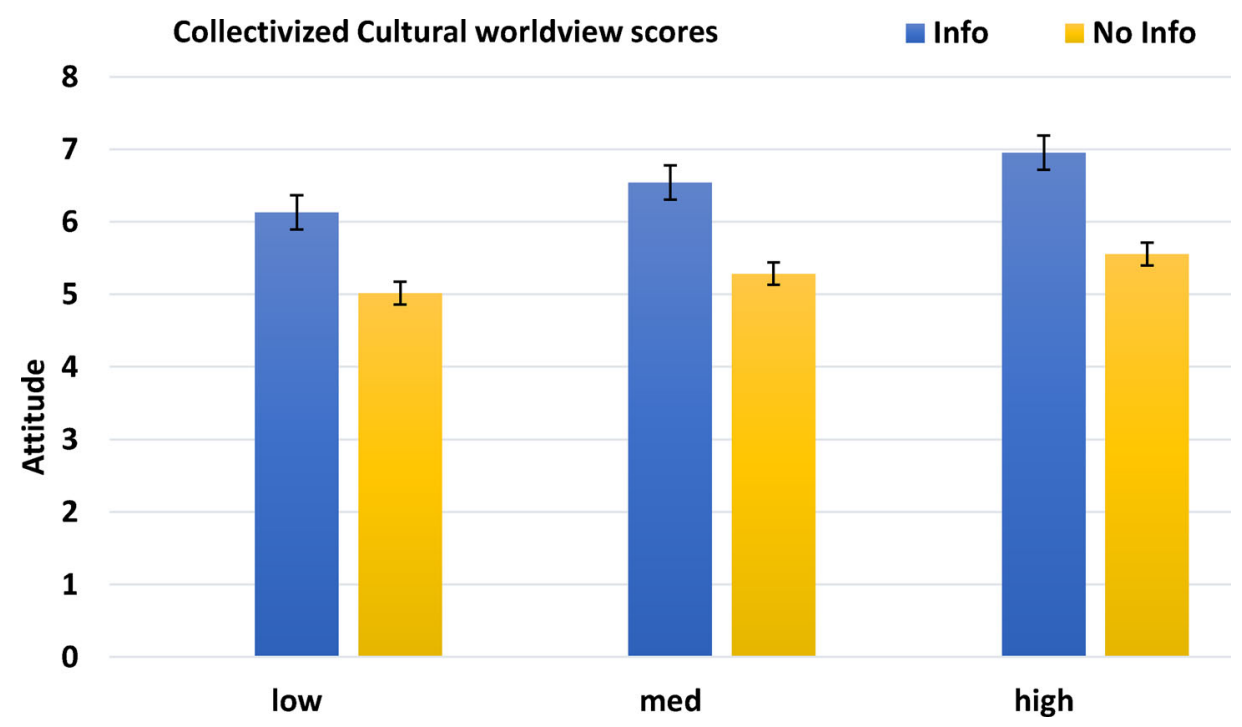

Figure 1. Visual display of attitude differences in the control group and treatment conditions with collectivists. Error bars denote standard error.

Information provision Figures 1-3 (hypothesis 2).

Note: High $=$ standard deviation above the mean. Low $=$ standard deviation below the mean. Information is coded 1 and no information is coded 0 .

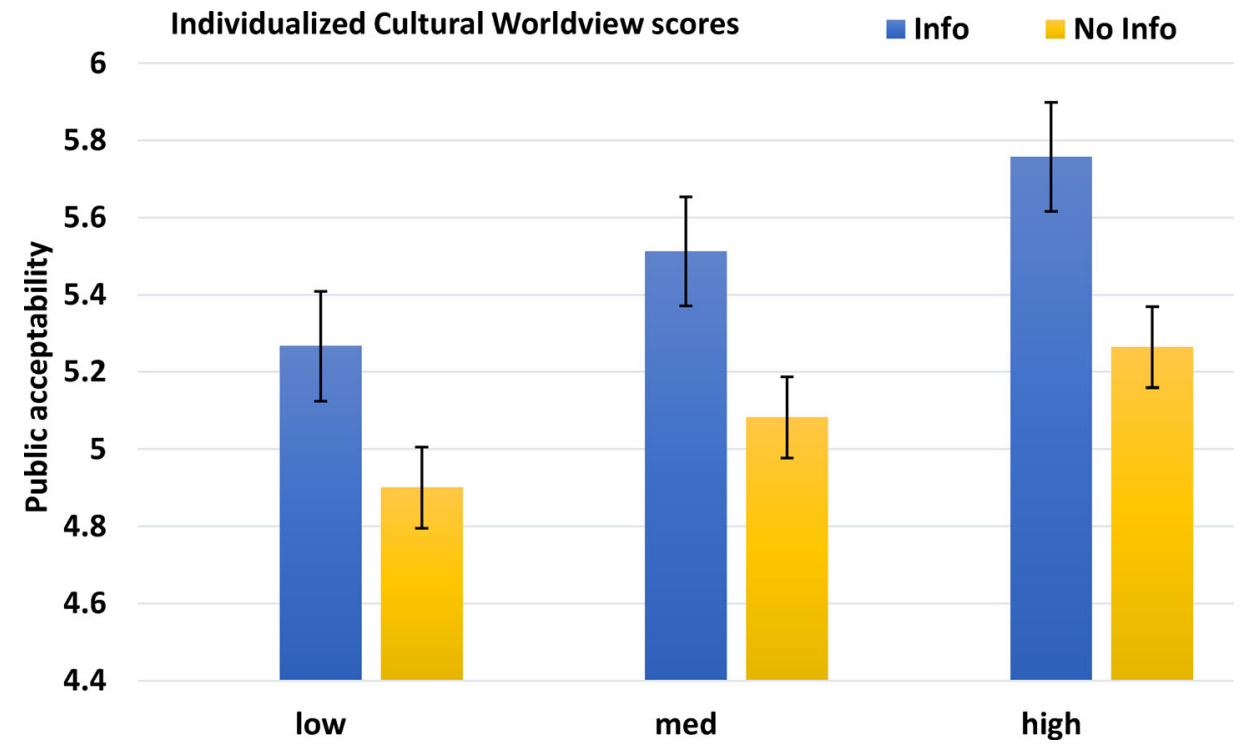

Figure 2. Visual display of acceptability differences in the control group and treatment conditions with individualists. Error bars denote standard error.

Note: Base value for this figure is 4.4. High = standard deviation above the mean. Low $=$ standard deviation below the mean. Information is coded 1 and no information is coded 0 .

positive attitudes and higher acceptability of sustainable land use zoning policy. When cultural worldviews were controlled, participants who received the information expressed a significantly more positive attitude and higher acceptability of sustainable 
Collectivized Cultrual Worldview scores $\quad$ Info No Info

7

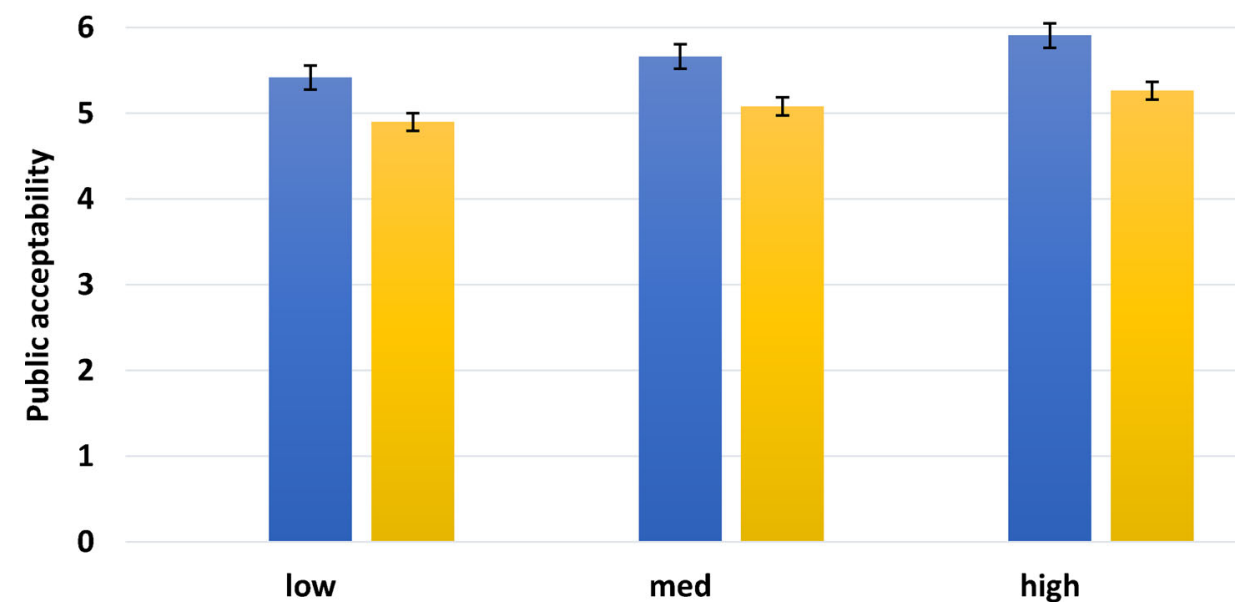

Figure 3. Visual display of acceptability differences in the control group and treatment conditions with collectivists. Error bars denote standard error.

Note: High $=$ standard deviation above the mean. Low $=$ standard deviation below the mean. Information is coded 1 and no information is coded 0 .

land use policy than the control group. Overall, the information effect is strong among those with low levels of attitude and acceptability (individualists) as collectivists already had a positive attitude and higher acceptability of sustainable land use zoning policy. Still, the information effect on attitudes was stronger in individualists, while the information effect on policy acceptability was stronger in collectivists. The finding that information is associated with a more positive attitude and acceptability of land use zoning policy aligns with previous research, demonstrating that providing the information is associated with more favorable attitudes toward climate change mitigation (Spence and Pidgeon 2010), and increased acceptance of sustainable land use policy (Pleger, Lutz, and Sager 2018). A possible explanation for the significant information effect in this study could be that participants lacked knowledge and awareness about policy impacts due to the absence of public policy in the last 30 years of the Somali conflict and, hence, developed knowledge about sustainable land use policy benefits from the information provided. This illustration is consistent with the knowledge deficit model's assumptions that if people are correctly informed, they are likely to develop favorable attitudes and change their behavior (Schultz 2002). The need for grassroots awareness in the light of environmental conditions in Somalia has been voiced in previous studies (Jama et al. 2020). Altogether, information provision effectively induces a positive attitude and sustainable land use zoning policy acceptability in Somalia, which is promising for communication and policy practitioners to steer sustainable land use practice.

In partial support of our third hypothesis, when the information was framed in terms of individualized and collectivized arguments, participants evaluated arguments that correspond with their cultural worldviews compared to the arguments that compete with them. Although the interaction is negligible, individualists evaluated individualized arguments more positively than collectivized arguments $\left(\mathrm{H}_{3 \mathrm{a}}\right.$ is supported), and collectivists evaluated collectivized arguments more positively than individualized 


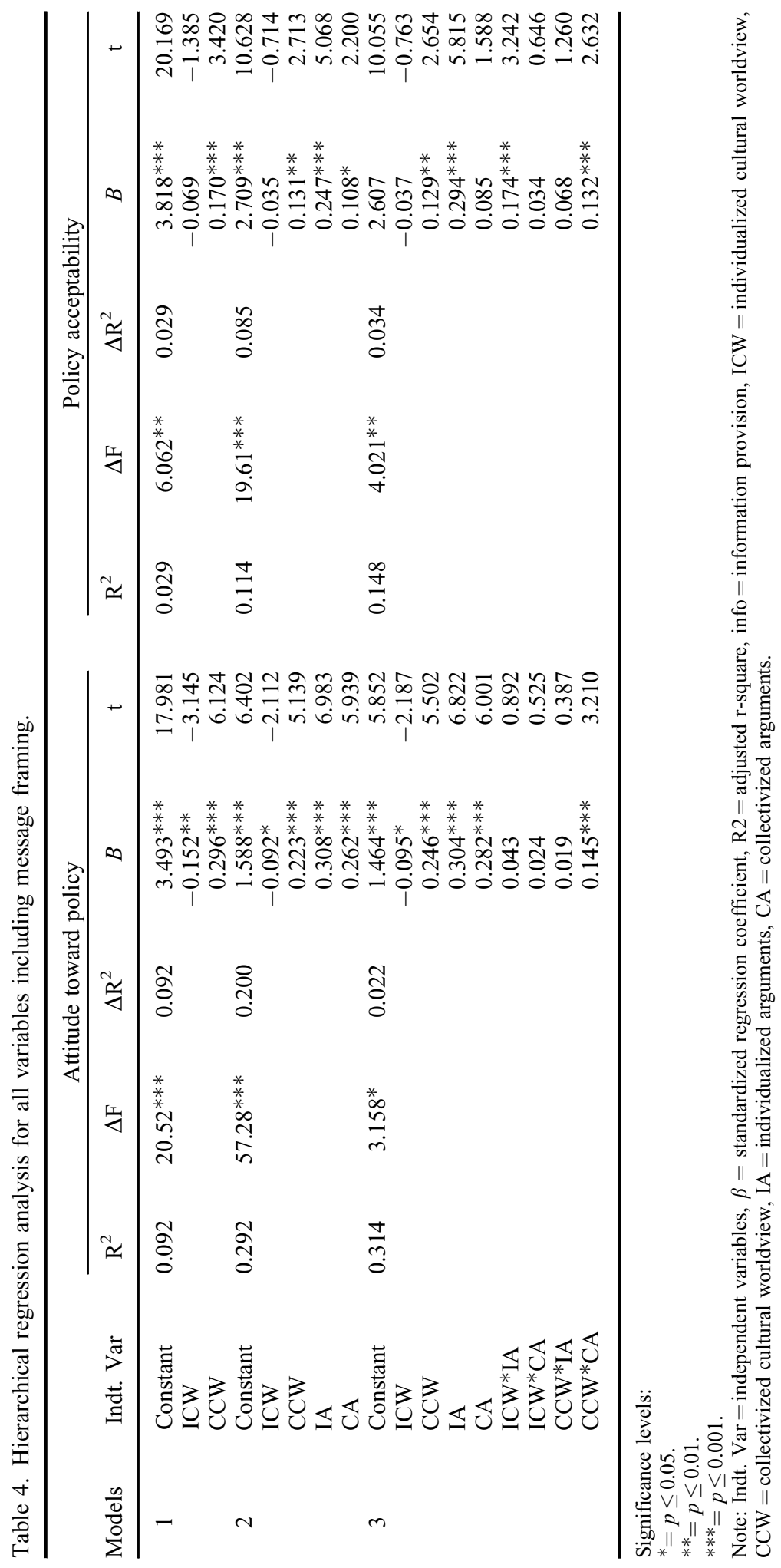




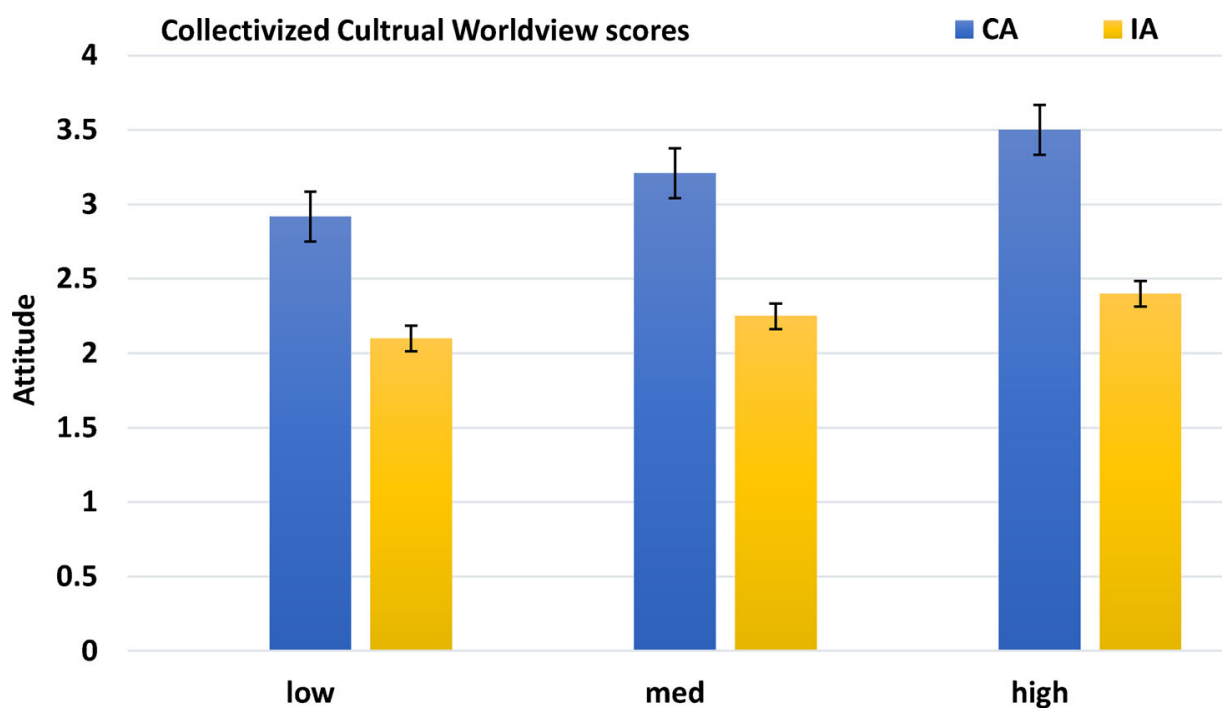

Figure 4. Differential effects of argument types on the collectivists' attitudes toward land use policy. The figure is generated from the values of unstandardized coefficients, standard deviation, and the mean of independent and dependent variables and their interaction term. Error bars denote standard error.

Message framing Figures 4-6 (hypothesis three).

Note: $\mathrm{CA}=$ collectivized arguments and $\mathrm{IA}=$ individualized arguments. High $=$ standard deviation above the mean. Low $=$ standard deviation below the mean.

Individualized Cultural Worldview scores

$\square$ CA $\quad$ IA

4.5

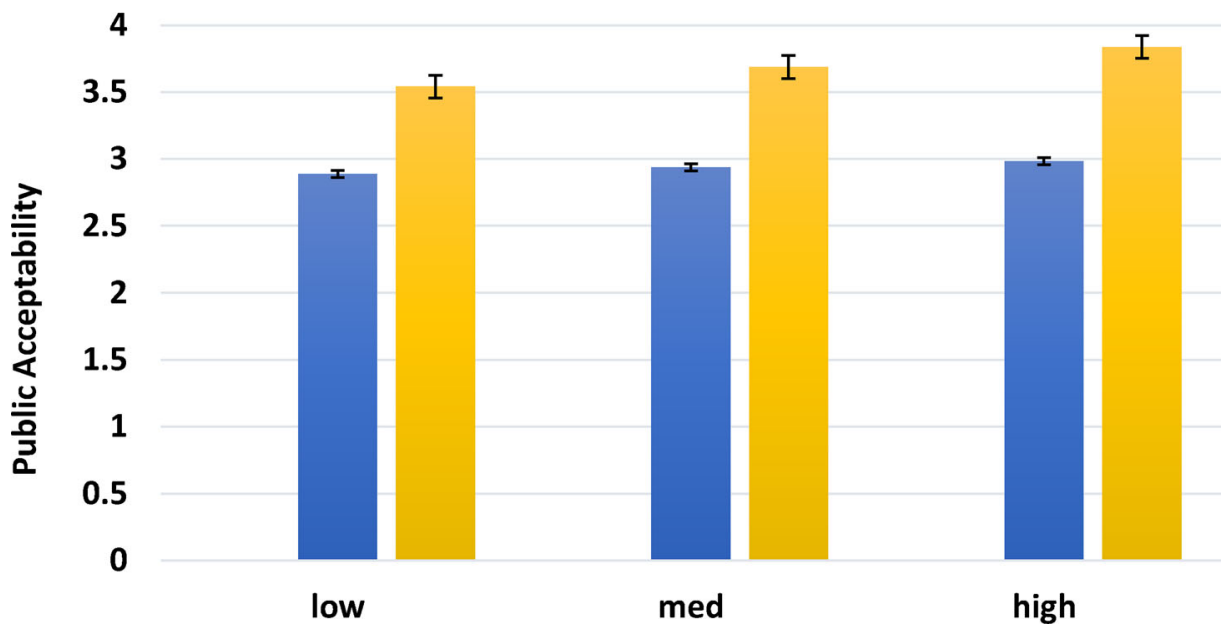

Figure 5. Differential effects of argument types on individualists' policy acceptability. The figure is generated from the values of unstandardized coefficients, standard deviation, and the mean of independent and dependent variables and their interaction term. Error bars denote standard error.

Note: $\mathrm{CA}=$ collectivized arguments and $\mathrm{IA}=$ individualized arguments. High $=$ standard deviation above the mean. Low $=$ standard deviation below the mean. 


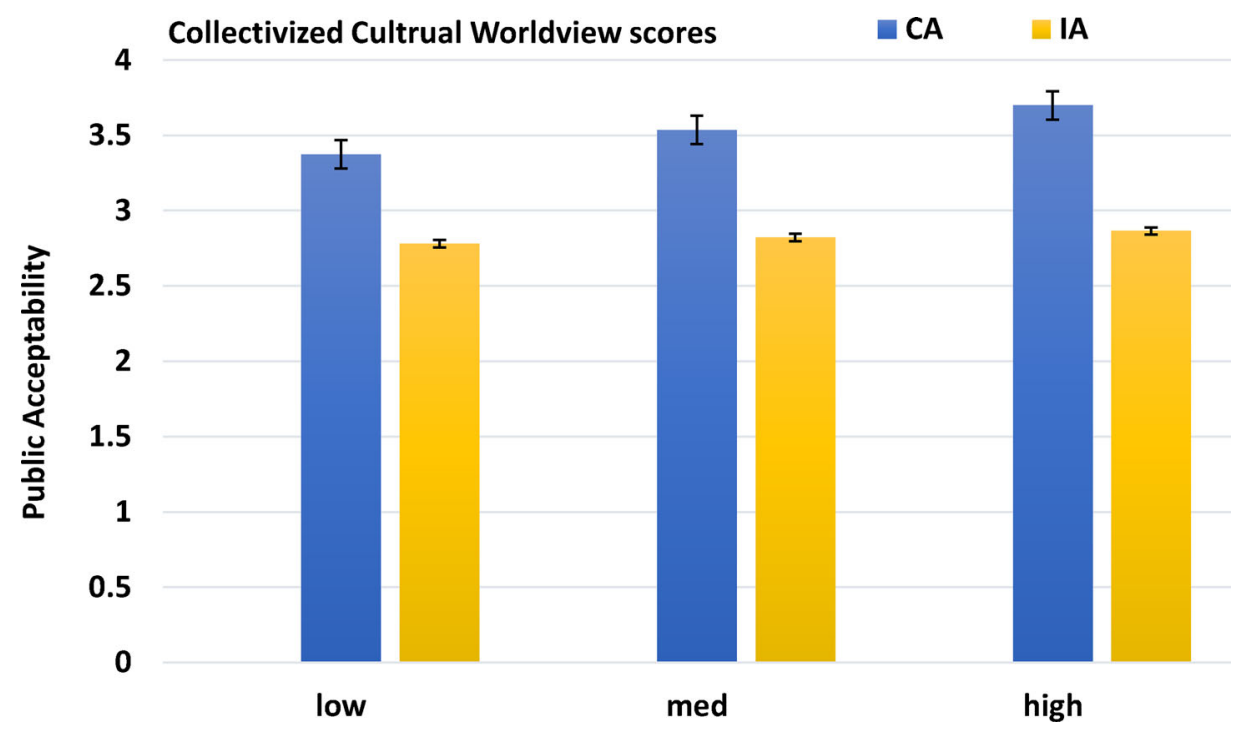

Figure 6. Differential effects of argument types on collectivists' policy acceptability. The figure is generated from the values of unstandardized coefficients, standard deviation, and the mean of independent and dependent variables and their interaction term. Error bars denote standard error.

Note: $\mathrm{CA}=$ collectivized arguments and $\mathrm{IA}=$ individualized arguments. High $=$ standard deviation above the mean. Low $=$ standard deviation below the mean.

arguments $\left(\mathrm{H}_{3 \mathrm{~b}}\right.$ is supported) which may indicate that people who draw upon selfinterest values respond more positively to self-enhancement arguments, and people who draw upon altruistic values respond more positively to pro-social and pro-environmental arguments. This interaction between cultural worldviews and argument types means that cultural worldviews moderated the message framing effects on participants' attitudes and acceptability. However, the interaction between individualized worldview and individualized arguments was statistically significant only within policy acceptability analysis.

Nevertheless, the attitude toward sustainable land use zoning policy was most strongly predicted by collectivized arguments, while individualized arguments most strongly predicted policy acceptability. Here a question arises: why different arguments predict attitude and acceptability? A possible account could be that collectivized arguments persuaded participants' moral feelings hence induced change in attitude. Moral consideration thus guided such evaluations (Bolderdijk et al. 2013). On the other hand, land use decisions often involve direct effects; therefore, salient issues such as perceived costs and self-interest may challenge moral feelings and obscure the participants with positive attitudes to perform the corresponding behavior. This would align with the assumption of cost saliency and self-serving bias, which may be well suited in low-income settings such as Somalia.

\subsection{Implications on sustainable land use policy in Somalia}

This study has important implications for practitioners of sustainable land use policy communication. Previous research demonstrates that cultural worldviews matter for 
environmental policy acceptance (Cherry, Kallbekken, and Kroll 2017), and our results support this. Policy advocates the need to consider how sustainable land use policy contributes to and reflects these worldviews to avoid unnecessary policy setbacks. While our findings indicate that information provision can be at the forefront in promoting positive attitudes and improving public acceptability of sustainable land use policy in Somalia, policy advocates should be mindful that individual predispositions such as worldviews influence the effectiveness of the information. As people with different cultural worldviews interpret information differently (West, Bailey, and Winter 2010), differentiated arguments could be used when communicating with the general public. The message content should correspond with the different cultural worldview commitments to promote sustainable land use policy acceptability more effectively. Such an approach of target group segmentation was previously recommended in climate change communication (Graham and Abrahamse 2017). Although we could not determine why different arguments predict a positive attitude and higher acceptability, collectivized arguments seem to be more useful in attempts to induce a positive attitude, while individualized arguments seem to be more relevant to behaviors such as sustainable land use policy acceptability.

\subsection{Limitations}

Despite the positive results, this study is not without limitations. Our finding that a positive attitude and higher public acceptability of sustainable land use policy are predicted by collectivized and individualized arguments respectively highlights the challenge of predicting different outcomes, as it may require differentiated arguments. Future research would benefit from examining why collectivized arguments are more effective in predicting attitudes, and individualized arguments are more effective in predicting policy acceptability. Although it is not within the scope of this study, we did not explicitly consider the degree to which perceived costs and direct involvement can influence the message framing effect. Future research may still examine whether these issues influence the effect of message framing. The study participants were slightly dominated by urban residents with a slightly higher educational level than the entire population average, this might be due to the high illiteracy rate and poor internet penetration in sparsely populated areas. Future studies may compare different socioeconomic and political stratifications. However, this limitation may not be a major concern as $75 \%$ of the Somali population is under the age of 30 (UNFPA 2014). Aside from these, the knowledge generated in this study is pertinent for formulating policy in Somalia.

\section{Conclusion}

This study demonstrates that cultural worldviews play an important role in the effectiveness of persuasive messages to induce positive attitudes and improve acceptability of sustainable land use zoning policy. This is crucial for implementing policies to steer sustainable land use practice and reduce deforestation. The findings of this study provide important implications for sustainable land use policy communications practitioners. When communicating the potential benefits of sustainable land use zoning policy to the general public, policy advocates should be aware that people with different cultural worldviews are susceptible to different arguments. This suggests the 
importance of avoiding the "one-size fits all" approach and framing policy communications effectively to better reflect the public's preferences and concerns. Since a single framing strategy may appeal only to a specific segment of the public, different arguments can be used when communicating policy with large populations. Tailoring these different arguments to peoples' cultural worldviews is a more efficient means to induce positive attitudes and higher acceptability of sustainable land use zoning policy. This requires identifying the context-specific cultural worldviews and preferences to design evidence-based persuasive arguments that can better appeal to the general public.

\section{References}

Abrahamse, Wokje, Linda Steg, Charles Vlek, and Talib Rothengatter. 2007. "The Effect of Tailored Information, Goal Setting, and Tailored Feedback on Household Energy Use, Energy-Related Behaviors, and Behavioral Antecedents." Journal of Environmental Psychology 27 (4): 265-276. doi:10.1016/j.jenvp.2007.08.002.

Arpan, Laura M., Xiaojing Xu, Arthur A. Raney, Chien fei Chen, and Zihan Wang. 2018. "Politics, Values, and Morals: Assessing Consumer Responses to the Framing of Residential Renewable Energy in the United States." Energy Research \& Social Science 46: 321-331. doi:10.1016/j.erss.2018.08.007.

Barr, Stewart, and Andrew W. Gilg. 2007. "A Conceptual Framework for Understanding and Analyzing Attitudes towards Environmental Behaviour." Geografiska Annaler, Series B: Human Geography 89 (4): 361-379. doi:10.1111/j.1468-0467.2007.00266.x.

Bolderdijk, J. W., L. Steg, E. S. Geller, P. K. Lehman, and T. Postmes. 2013. "Comparing the Effectiveness of Monetary versus Moral Motives in Environmental Campaigning." Nature Climate Change 3 (4): 413-416. doi:10.1038/nclimate1767.

Bolognesi, M., A. Vrieling, F. Rembold, and H. Gadain. 2015. "Rapid Mapping and Impact Estimation of Illegal Charcoal Production in Southern Somalia Based on WorldView-1 Imagery." Energy for Sustainable Development 25: 40-49. doi:10.1016/j.esd.2014.12.008.

Bruggeman, Derek, Patrick Meyfroidt, and Eric F. Lambin. 2015. "Production Forests as a Conservation Tool: Effectiveness of Cameroon's Land Use Zoning Policy." Land Use Policy 42: 151-164. doi:10.1016/j.landusepol.2014.07.012.

Busse, Maria, and Rosemarie Siebert. 2018. "Acceptance Studies in the Field of Land Use: A Critical and Systematic Review to Advance the Conceptualization of Acceptance and Acceptability." Land Use Policy 76: 235-245. (May): doi:10.1016/j.landusepol.2018.05.016.

Cherry, Todd L., Steffen Kallbekken, and Stephan Kroll. 2017. "Accepting Market Failure: Cultural Worldviews and the Opposition to Corrective Environmental Policies." Journal of Environmental Economics and Management 85: 193-204. doi:10.1016/j.jeem.2017.05.004. 
Chong, Dennis, and James N. Druckman. 2007. "Framing Theory." Annual Review of Political Science 10 (1): 103-126. doi:10.1146/annurev.polisci.10.072805.103054.

Douglas, M. 1970. Natural Symbols: Explorations in Cosmology. London: Taylor \& Francis Ltd.

Douglas, Mary, and Aaron Wildavsky. 1983. Risk and Culture: An Essay on the Selection of Technological and Environmental Dangers. Oakland: University of California Press.

Druckman, James N., Donald P. Green, James H. Kuklinski, and Arthur Lupia. 2011. "Experimentation in Political Science." In Cambridge Handbook of Experimental Political Science, edited by James N. Druckman, Donald P. Greene, James H. Kuklinski, and Arthur Lupia, 3-12, New York: Cambridge University Press.

Geneletti, Davide. 2013. "Assessing the Impact of Alternative Land-Use Zoning Policies on Future Ecosystem Services." Environmental Impact Assessment Review 40 (1): 25-35. doi: 10.1016/j.eiar.2012.12.003.

Graham, Thomas, and Wokje Abrahamse. 2017. "Communicating the Climate Impacts of Meat Consumption: The Effect of Values and Message Framing." Global Environmental Change 44: 98-108. doi:10.1016/j.gloenvcha.2017.03.004.

Halik, Abdul, and Marco Verweij. 2018. "Socio-Cultural Diversity and Public Preferences for Coral Reef Management Options in Indonesia." Ocean \& Coastal Management 162: 13-23. doi:10.1016/j.ocecoaman.2017.08.012.

Hamenstädt, Ulrich. 2011. "Methodische aspekte." In Die Logik Des Politikwissenschaftlichen Experiments: Methodenentwicklung Und Praxisbeispiel, 1st ed. edited by U. Hamenstädt, 63-123. Wiesbaden: VS-Verl. https://www.springer.com/de/book/9783531186191

Hardisty, David J., Eric J. Johnson, and Elke U. Weber. 2010. “A Dirty Word or a Dirty world?: Attribute Framing, Political Affiliation, and Query Theory." Psychological Science 21 (1): 86-92. doi:10.1177/09567976093555572.

Hayes, Andrew F. 2013. Mediation, Moderation, and Conditional Process Analysis. Introduction to Mediation, Moderation, and Conditional Process Analysis: A Regression-Based Approach. New York: Guilford Publications.

Hoogstra-Klein, Marjanke A., Dwiko B. Permadi, and Yurdi Yasmi. 2012. "The Value of Cultural Theory for Participatory Processes in Natural Resource Management." Forest Policy and Economics 20: 99-106. doi:10.1016/j.forpol.2011.12.001.

Ingold, Karin. 2011. "Network Structures within Policy Processes: Coalitions, Power, and Brokerage in Swiss Climate Policy.” Policy Studies Journal 39 (3): 435-459. doi:10.1111/j. 1541-0072.2011.00416.x.

Iyengar, Shanto. 2011. "Laboratory Experiments in Political Science." In Cambridge Handbook of Experimental Political Science, edited by J. N. Druckman, D. P. Green, J. H. Kuklinski, and A. Lupia, 73-88. New York: Cambridge University Press.

Jama, Osman M., Guijian Liu, Abdishakur W. Diriye, Balal Yousaf, Ibrahim Basiru, and Abdulhakim M. Abdi. 2020. "Participation of Civil Society in Decisions to Mitigate Environmental Degradation in Post-Conflict Societies: Evidence from Somalia." Journal of Environmental Planning and Management 63 (9): 1695-1621. doi:10.1080/09640568.2019. 1685957.

Jang, S. Mo. 2013. "Framing Responsibility in Climate Change Discourse: Ethnocentric Attribution Bias, Perceived Causes, and Policy Attitudes." Journal of Environmental Psychology 36: 27-36. doi:10.1016/j.jenvp.2013.07.003.

Jose, Paul E. 2013. ModGraph-I: A Programme to Compute Cell Means for the Graphical Display of Moderational Analyses. Wellington, New Zealand: Victoria University of Wellington.

Kahan, Dan M., and Donald Braman. 2006. "Cultural Cognition and Public Policy." Yale Law Policy Review 24 (149): 147-170.

Kiage, Lawrence M. 2013. "Perspectives on the Assumed Causes of Land Degradation in the Rangelands of Sub-Saharan Africa." Progress in Physical Geography: Earth and Environment 37 (5): 664-684. doi:10.1177/0309133313492543.

Kriesi, Hanspeter, and Maya Jegen. 2001. "The Swiss Energy Policy Elite: The Actor Constellation of a Policy Domain in Transition." European Journal of Political Research 39 (2): 251-287. doi:10.1111/1475-6765.00577.

Lambin, Eric F., Patrick Meyfroidt, Ximena Rueda, Allen Blackman, Jan Börner, Paolo Omar Cerutti, Thomas Dietsch., et al. 2014. "Effectiveness and Synergies of Policy Instruments 
for Land Use Governance in Tropical Regions." Global Environmental Change 28: 129-140. doi:10.1016/j.gloenvcha.2014.06.007.

Leiserowitz, Anthony. 2006. "Climate Change Risk Perception and Policy Preferences: The Role of Affect, Imagery, and Values." Climatic Change 77 (1-2): 45-72. doi:10.1007/s10584006-9059-9.

Lima, Maria Luisa, and Paula Castro. 2005. "Cultural Theory Meets the Community: Worldviews and Local Issues." Journal of Environmental Psychology 25 (1): 23-35. doi:10. 1016/j.jenvp.2004.11.004.

Lucke, Doris. 1995. “Akzeptanz." Legitimität in der Abstimmungsgesellschaft. Opladen: Leske + Budrich.

Markle, Gail. 2019. "Understanding Pro-Environmental Behavior in the US: Insights from GridGroup Cultural Theory and Cognitive Sociology.” Sustainability (Switzerland) 11 (2): 532. doi:10.3390/su11020532.

McKenzie-Mohr, Doug, and P. Wesley Schultz. 2014. "Choosing Effective Behavior Change Tools." Social Marketing Quarterly 20 (1): 35-46. doi:10.1177/1524500413519257.

Nolte, Christoph, Arun Agrawal, Kirsten M. Silvius, and S. Soares Filho Britaldo. 2013. "Governance Regime and Location Influence Avoided Deforestation Success of Protected Areas in the Brazilian Amazon." Proceedings of the National Academy of Sciences of the United States of America 110 (13): 4956-4961. doi:10.1073/pnas.1214786110.

Nolte, Christoph, Beatriz Gobbi, Yann Le Polain de Waroux, María Piquer-Rodríguez, Van Butsic, and Eric F. Lambin. 2017. "Decentralized Land Use Zoning Reduces Large-Scale Deforestation in a Major Agricultural Frontier." Ecological Economics 136: 30-40. doi:10. 1016/j.ecolecon.2017.02.009.

Oduori, S. M., F. Rembold, O. H. Abdulle, and R. Vargas. 2011. "Assessment of Charcoal Driven Deforestation Rates in a Fragile Rangeland Environment in North Eastern Somalia Using Very High Resolution Imagery." Journal of Arid Environments 75 (11): 1173-1181. doi:10.1016/j.jaridenv.2011.05.003.

Omuto, C. T., Z. Balint, and M. S. Alim. 2014. "A Framework for National Assessment of Land Degradation in the Drylands: A Case Study of Somalia." Land Degradation \& Development 25 (2): 105-119. doi:10.1002/ldr.1151.

Omuto, C. T., R. R. Vargas, M. S. Alim, A. Ismail, A. Osman, and H. M. Iman. 2009. Land Degradation Assessment and a Monitoring Framework in Somalia. FAO-SWALIM Technical Report No. L-14. Nairobi, Kenya: FAO-SWALIM. www.faoswalim.org

Pleger, Lyn E. 2017. "Voters' Acceptance of Land Use Policy Measures: A Two-Level Analysis." Land Use Policy 63: 501-513. doi:10.1016/j.landusepol.2017.02.001.

Pleger, Lyn E., Philipp Lutz, and Fritz Sager. 2018. "Public Acceptance of Incentive-Based Spatial Planning Policies: A Framing Experiment." Land Use Policy 73: 225-238. doi:10. 1016/j.landusepol.2018.01.022.

Price, Jennifer C., Iain A. Walker, and Fabio Boschetti. 2014. "Measuring Cultural Values and Beliefs about Environment to Identify Their Role in Climate Change Responses." Journal of Environmental Psychology 37: 8-20. doi:10.1016/j.jenvp.2013.10.001.

Rembold, F., S. M. Oduori, H. Gadain, and P. Toselli. 2013. "Mapping Charcoal Driven Forest Degradation during the Main Period of al Shabaab Control in Southern Somalia." Energy for Sustainable Development 17 (5): 510-514. doi:10.1016/j.esd.2013.07.001.

Rissman, Adena R., Patrice A. Kohl, and Chloe B. Wardropper. 2017. "Public Support for Carrot, Stick, and No-Government Water Quality Policies." Environmental Science \& Policy 76: 82-89. (November 2016): doi:10.1016/j.envsci.2017.04.012.

Sabatier, Paul A., and Christopher M. Weible. 2014. Theories of the Policy Process Boulder, CO: Westview Press.

Scannell, Leila, and Robert Gifford. 2013. "Personally Relevant Climate Change: The Role of Place Attachment and Local versus Global Message Framing in Engagement." Environment and Behavior 45 (1): 60-85. doi:10.1177/0013916511421196.

Schade, Jens, and Bernhard Schlag. 2003. "Acceptability of Urban Transport Pricing Strategies." Transportation Research Part F: Traffic Psychology and Behaviour 6 (1): 45-61. doi:10. 1016/S1369-8478(02)00046-3.

Schultz, P Wesley. 2002. "Knowledge, Information, and Household Recycling: Examining the Knowledge-Deficit Model of Behavior Change." In New Tools for Environmental Protection: Education, Information, and Voluntary Measures, edited by Thomas Dietz and 
Paul C. Stern, 67-82. Washington, DC: National Research Council. https://doi.org/10. $17226 / 10401$

Schwarz, Michiel, and Michael Thompson. 1990. Divided we Stand: Redefining Politics, Technology, and Social Choice. Philadelphia: University of Pennsylvania Press.

Smith, Vernon L. 1994. "Economics in the Laboratory." Journal of Economic Perspectives 8 (1): 113-131. doi:10.1257/jep.8.1.113.

Spence, Alexa, and Nick Pidgeon. 2010. "Framing and Communicating Climate Change: The Effects of Distance and Outcome Frame Manipulations." Global Environmental Change 20 (4): 656-667. doi:10.1016/j.gloenvcha.2010.07.002.

Steg, Linda, and Inge Sievers. 2000. "Cultural Theory and Individual Perceptions of Environmental Risks." Environment and Behavior 32 (2): 250-269. doi:10.1177/00139160021972513.

Steg, Linda, and Charles Vlek. 2009. "Encouraging Pro-Environmental Behaviour: An Integrative Review and Research Agenda." Journal of Environmental Psychology 29 (3): 309-317. doi:10.1016/j.jenvp.2008.10.004.

Suarez, Andres, Paola Andrea Árias-Arévalo, and Eliana Martínez-Mera. 2018. "Environmental Sustainability in Post-Conflict Countries: Insights for Rural Colombia." Environment, Development and Sustainability 20 (3): 997-1015. doi:10.1007/s10668-017-9925-9.

Teel, Tara L., Alan D. Bright, Michael J. Manfredo, and Jeffrey J. Brooks. 2006. "Evidence of Biased Processing of Natural Resource-Related Information: A Study of Attitudes toward Drilling for Oil in the Arctic National Wildlife Refuge." Society \& Natural Resources 19 (5): 447-463. doi:10.1080/08941920600561140.

Thompson, Michael, Richard Ellis, and Aaron Wildavsky. 1990. Cultural Theory. Boulder, CO: Westview Press.

UNDP. 2012. Energy Alternatives to Charcoal Production: Findings and Proposals. Nairobi: UNDP.

UNEP. 2005. The State of the Environment in Somalia: A Desk Study. UNEP. https://www. unep.org/resources/report/state-environment-somalia-desk-study

UNFPA. 2014. Population Estimation Survey 2014. United Nations Population Fund - Somalia, Nairobi: UNFPA.

USAGM. 2013. Media Use in Somalia. Washington, DC: United States Agency for Global Media/Gallup.

Vaske, Jerry J., and Maureen P. Donnelly. 1999. "A Value-Attitude-Behavior Model Predicting Wildland Preservation Voting Intentions." Society and Natural Resources 12 (6): 523-537. doi:10.1080/089419299279425.

Verweij, Marco, Mary Douglas, Richard Ellis, Christoph Engel, Frank Hendriks, Susanne Lohmann, Steven Ney, Steve Rayner, and Michael Thompson. 2006. "Clumsy Solutions for a Complex World: The Case of Climate Change." Public Administration 84 (4): 817-843. doi:10.1111/j.1540-8159.2005.09566.x-i1.

von Borgstede, Chris, Maria Andersson, and André Hansla. 2014. "Value-Congruent Information Processing: The Role of Issue Involvement and Argument Strength." Basic and Applied Social Psychology 36 (6): 461-477. doi:10.1080/01973533.2014.958226.

Waaben Thulstrup, Andreas, Didier Habimana, Indira Joshi, and Simon Mumuli Oduori. 2020. "Uncovering the Challenges of Domestic Energy Access in the Context of Weather and Climate Extremes in Somalia." Weather and Climate Extremes 27 (July 2017): 100185100181. doi:10.1016/j.wace.2018.09.002.

West, J., I. Bailey, and M. Winter. 2010. "Renewable Energy Policy and Public Perceptions of Renewable Energy: A Cultural Theory Approach." Energy Policy 38 (10): 5739-5748. doi: 10.1016/j.enpol.2010.05.024.

Williams, Kathryn J. H. 2014. "Public Acceptance of Plantation Forestry: Implications for Policy and Practice in Australian Rural Landscape." Land Use Policy 38: 346-354. doi:10. 1016/j.landusepol.2013.11.023.

Williams, Kathryn. 2011. "Relative Acceptance of Traditional and Non-Traditional Rural Land Uses: Views of Residents in Two Regions, Southern Australia." Landscape and Urban Planning 103 (1): 55-63. doi:10.1016/j.landurbplan.2011.05.012. 